\title{
Food safety and food security: Mapping relationships
}

\author{
Wanda Martin ${ }^{a *}$ and Kathleen Perkin ${ }^{\mathrm{b}}$ \\ Centre for Addictions Research of British Columbia, University of Victoria
}

Submitted April 17, 2015 / Revised June 5, 2015 / Accepted July 7, 2015 /

Published online January 14, 2016

Citation: Martin, W., \& Perkin, K. (2016). Food safety and food security: Mapping relationships.

Journal of Agriculture, Food Systems, and Community Development, 6(2), 13-24.

http://dx.doi.org/10.5304/jafscd.2016.062.001

Copyright (C) 2016 by New Leaf Associates, Inc.

\begin{abstract}
Food safety regulations designed for industrialscale food producers can create insurmountable challenges when applied to small-scale food producers. These challenges can make for a frustrating environment for food consumers, producers, and regulators, at times leading to tensions between food producers and people working in food safety. The objective of this study was to identify ways to reduce these tensions and

a * Corresponding author: Wanda Martin, Centre for Addictions Research of British Columbia, University of Victoria. Wanda Martin is now Assistant Professor, College of Nursing, University of Saskatchewan; Health Sciences Building, E-Wing, Room 4324; 104 Clinic Place; Saskatoon, SK S7N 5E5, Canada; +1-306-966-5429;

wanda.martin@usask.ca

b Kathleen Perkin, Research Coordinator, Centre for Addictions Research of British Columbia, University of Victoria.

Kathleen Perkin is now a Manager of Harm Reduction Policy, British Columbia Ministry of Health; 1515 Blanshard Street; Victoria, BC; +1-250-952-1578;

Kathleen.perkin@gov.bc.ca
\end{abstract}

\section{Authors Note}

This research was supported through a Canadian Institutes of Health doctoral research award and is part of Wanda Martin's dissertation work. promote intersectoral collaboration. We used concept mapping, a structured, participatory, mixed-method approach, to solicit ideas and synthesize input from those working in food safety and food security. We sent invitations to 96 individuals working in food safety or food security, and 50 completed the online concept mapping. Twenty-three participated in categorizing and ranking all the resulting statements. The findings were 'mapped' into six clusters: (1) communicating, (2) understanding intent, (3) educating, (4) understanding risk and regulation, (5) recognizing scale, and (6) enhancing partnerships. We further reduced these six clusters into three categories: "relationships," "education," and "context." Although there are no quick or easy ways to ease tensions between those working in food safety and food security, we suggest four practical ways to ease tensions to ensure safe and accessible food: (1) a collaborative group at a high regulatory level that shares authority is needed; (2) building relationships across disciplines should be considered as part of public health work; (3) regulatory documents should be written in plain language; and (4) food safety regulations should account for differences in scale of production with supportive resourcing. 


\section{Keywords}

concept mapping, food safety, food security, public health, regulations, small-scale production

\section{Introduction and Background}

Consumers increasingly are reporting their interest in purchasing food close to home from small-scale businesses rather than from large companies (Buckley, 2015; Dodds et al., 2014). However, local food supplies typically lag behind demand, in part because of the need for long-term, stable funding for community food projects (Mount et al., 2013). A primary barrier is that food safety regulations designed for industrial-scale food producers create all but insurmountable challenges when applied to small-scale food producers (McMahon, 2011). Community farms struggle to implement food safety programs designed for industrial-scale operations, resulting in consumers seeing the food as "less "food safe" (Hughes, 2010, p. 6). Little attention is given to the way that regulations and policies inhibit local food production (Goldberg, 2012). Even less attention is given to those who are expected to enforce these regulations. Positive interactions between people working in food safety and people who produce food can improve both compliance with food safety regulations and processing operations (Buckley, 2015). We argue that in order to improve access to safe and healthy local food, the people who produce and consume food and those who create and enforce food safety regulations need to understand each others' perspectives better.

This paper presents results from the first author's doctoral dissertation. Martin (2014) examined how people enforcing food safety regulations that are legislated and mandated by the provincial and federal governments in Canada interact with people supporting local food initiatives, such as farmers markets, community kitchens, and urban agriculture. These types of initiatives fall under the umbrella of community food security, defined as a situation where community residents can obtain safe, culturally appropriate, and nutritionally adequate diet through a sustainable food system (Hamm \& Bellows, 2003). This is the definition adopted by the British Columbia (BC) Ministry of Health's
Food Security Core Public Health Program, which highlights supporting a sustainable food system through small-scale agriculture. Rideout, Seed, and Ostry (2006) conceptualize food security from a narrow definition of hunger, to a broad view of structural issues. In this paper we adopt the broad view using the term community food security.

Martin (2014) asked two main questions in this study: (1) how are the intersecting areas between food safety and community food security negotiated, and (2) what are the facilitators and constraints to collaboration? She used both situational analysis (Clarke, 2005) and concept mapping (Kane $\&$ Trochim, 2007). The results of the situational analysis indicate that food safety regulations are not created primarily to protect people from unsafe food, but are a vehicle for providing confidence in the market and among international trading partners (Martin, 2014). In this paper we report the concept mapping results.

\section{Food Safety}

Foodborne illness is the largest class of emerging infectious diseases in Canada (Weatherill, 2009). The Public Health Agency of Canada reports that over 30 pathogens cause 4 million episodes of foodborne illness annually (Thomas et al., 2013). Microbes responsible for outbreaks are increasing in strength (Nestle, 2003). In spite of efforts to reduce foodborne illness, rates have risen over the past ten years (Morris, 2011). The need for a robust health protection service is clear.

Numerous authors suggest that industrial, "factory" food production systems, which necessitate overuse of antibiotics in animals, are a threat to a safe food supply (Buckley, 2015; McMahon, 2011; Nestle, 2003; Worosz, Knight, Harris, \& Conner, 2008). To deal with the increasing threat posed by industrial food production, regulators introduced science-based rules and controls to stem the flow of foodborne disease rather than requiring industry to reduce the scale of food production. If we assume that all foods of animal origin (i.e., meat, dairy products, and eggs) present similar risks, then it is reasonable to expect that one set of regulations would provide adequate protection from foodborne illness at any scale of food production. However, the animal is not 
necessarily the problem as much as is the production method.

\section{Conflicts in Food Safety and Local Food}

In 2004 the BC Ministry of Health made changes to the Meat Inspection Regulation section of the Food Safety Act ("Food Safety Act Meat Inspection Regulation," 2004), leading to concern among people working in community food security. The intent of the BC Meat Inspection Regulation change was to standardize meat production in the province, protect public health, and foster confidence in the BC food supply (McMahon, 2011). However, impacts of the new regulations on smallscale producers included higher slaughter costs, lower profit margins, lost revenues, loss of farm status, and reduced livestock production (Johnson, 2008). The resulting lack of product made it difficult to source locally produced meat and constituted a serious economic impact on producers and their rural communities. The changes in the meat regulations resulted in a loud outcry in the community food security world, fueling overall cynicism toward food safety regulations.

Other parts of Canada and other countries have experienced similar conflicts between food safety regulations and food producers. A smallscale Manitoba farmer received a provincial government award for pastured pork prosciutto, yet months later had the product confiscated by health inspectors claiming it was unfit for human consumption (Anderson, 2013). Customers and the farmer were frustrated by the destruction of five years' worth of product without any testing for contaminants (CBC News, 2013). In Brazil food safety regulations have blocked traditional food production, hampering revitalization of rural areas (da Cruz \& Menasche, 2014). In the state of Michigan, small-scale producers in the red meat sector have encountered challenges implementing food safety plans and have had to navigate inconsistent food safety rule interpretation by regulators (Worosz et al., 2008).

The purpose of this research was to examine how professionals working in both food safety and community food security initiatives, along with civil society members, work across differences to support a safe and accessible food supply. The objectives were to identify the source of tensions in this aspect of the food system, and identify ways to improve collaboration.

\section{Methods}

We used concept mapping methodology to identify ways to ease tensions between those in food safety and those in community food security. Concept mapping is a participatory process using both qualitative and quantitative analysis and allowing for diverse groups to contribute unique and varied perspectives on a specific issue. This method enables people to describe ideas in response to a question or statement (called a "focused prompt"), which translates to maps for visual representation, providing insight to practical approaches on a focused issue (Trochim, Cabrera, Milstein, Gallagher, \& Leischow, 2006). Participants not only contribute their responses to the research question, but also add to analysis by sorting and ranking all the responses. Group concept mapping is an online data collection platform developed by Concept Systems Incorporated. Details of concept mapping are available elsewhere (Kane \& Trochim, 2007; Trochim, 1989), but we describe the basic components below.

\section{Sample Selection}

We obtained institutional human subjects research approval prior to study recruitment. We invited a wide range of participants involved in food safety and community food security, including national representatives of public health inspectors, community food security activists, food producers, public health officials, and interested academics, through an initial contact list of 96 people known to be working in community food security or food safety and who were engaged with various networks. This included people working in $\mathrm{BC}$ health authorities and provincial agencies, Toronto Public Health, provincial food security networks in Canada, Food Secure Canada, the Canadian Institute of Public Health Inspectors, the Canadian Food Inspection Agency, the BC Food Processors Association, and the BC Association of Farmers' Markets, as well as people in various academic settings, including the Canadian Association for Food Studies. The invitation directed participants 
to a website for online data collection. We also invited people to share the link with anyone they thought would be interested in participating.

\section{Brainstorming, Rating and Sorting}

We asked participants to respond online to what Kane and Trochim (2007) call a focused prompt. This is the first part of a sentence that allows participants to brainstorm ways to solve an issue. Our focused prompt was regarding ways to work better together: "The best way to ease tensions between those working in food safety and food security is..." Participants logged on to the site and could enter as many responses as they liked. All responses were anonymized and visible to other participants, allowing for one person's ideas to spark another's, mimicking what may happen in a focus group. The benefit of the online system is that everyone was free to make their statements without fear of criticism or controversy (Trochim, 1989). Fifty people submitted statements in response to the focused prompt. After participants submitted their response statements, they were invited back to sort all unique statements into categories of their own choosing, and to rank statements on dimensions of importance and feasibility using a 5 -point Likert scale $(1=$ not at all important, $5=$ extremely important; $1=$ not at all feasible, $5=$ extremely feasible). Twentythree participants completed the sorting (seven of whom identified as working in food safety); 22 rated the statements on importance and 21 rated the statements on feasibility. Kane and Trochim (2007) report that typically 10 to 40 people participate in concept mapping, providing a variety of opinions and that this number is adequate to form a good framework.

\section{Statistical Analysis}

The Group Concept Mapping platform includes all aspects of the method, including analysis and generation of results in the form of maps. The information from sorting statements creates a similarity matrix, and the statements are then plotted on a map using nonmetric multidimensional scaling (MDS) (Trochim, 1989). As is typical for concept mapping, we used two dimensions in order to produce $\mathrm{X}$, Y coordinates suitable for visual representation on a two-dimensional surface (Figure 1). The maps, also known as point maps or scatter plots, position statements close together if many participants grouped them in the same categories, and far apart if few or no participants grouped them together (Kane \& Trochim, 2007).

Based on the point map, statements were combined into clusters using hierarchical cluster analysis that partitions the configuration into nonoverlapping clusters in two-dimensional space, called a cluster map (Trochim, 1989) (Figure 2). The cluster shapes are defined by the point map. Cluster colors are randomly assigned by the software program. We considered how many clusters there should be based on what seemed to

\section{Figure 1. Point Map of Participants' Statements $(N=60)$}

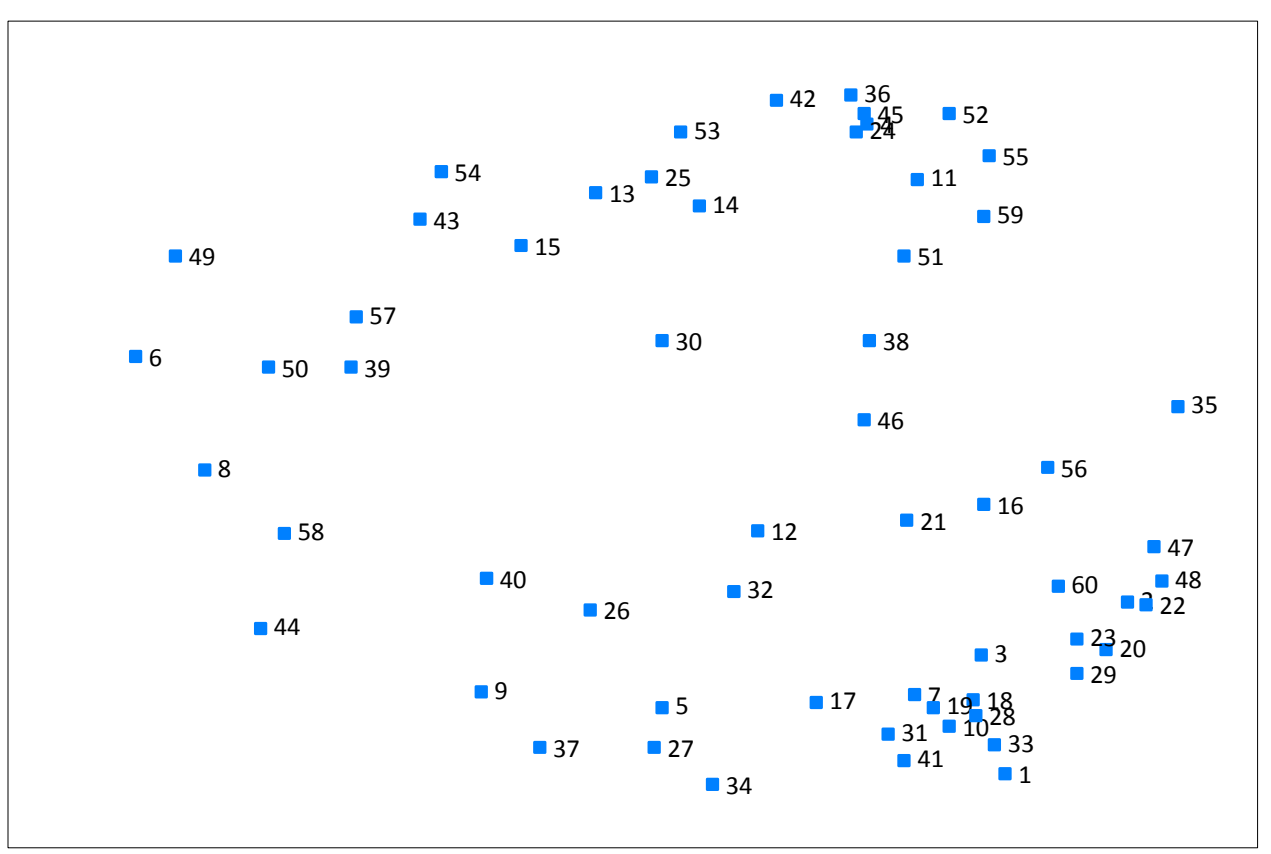


Figure 2. Cluster Map Based on Point Map (Figure 1)

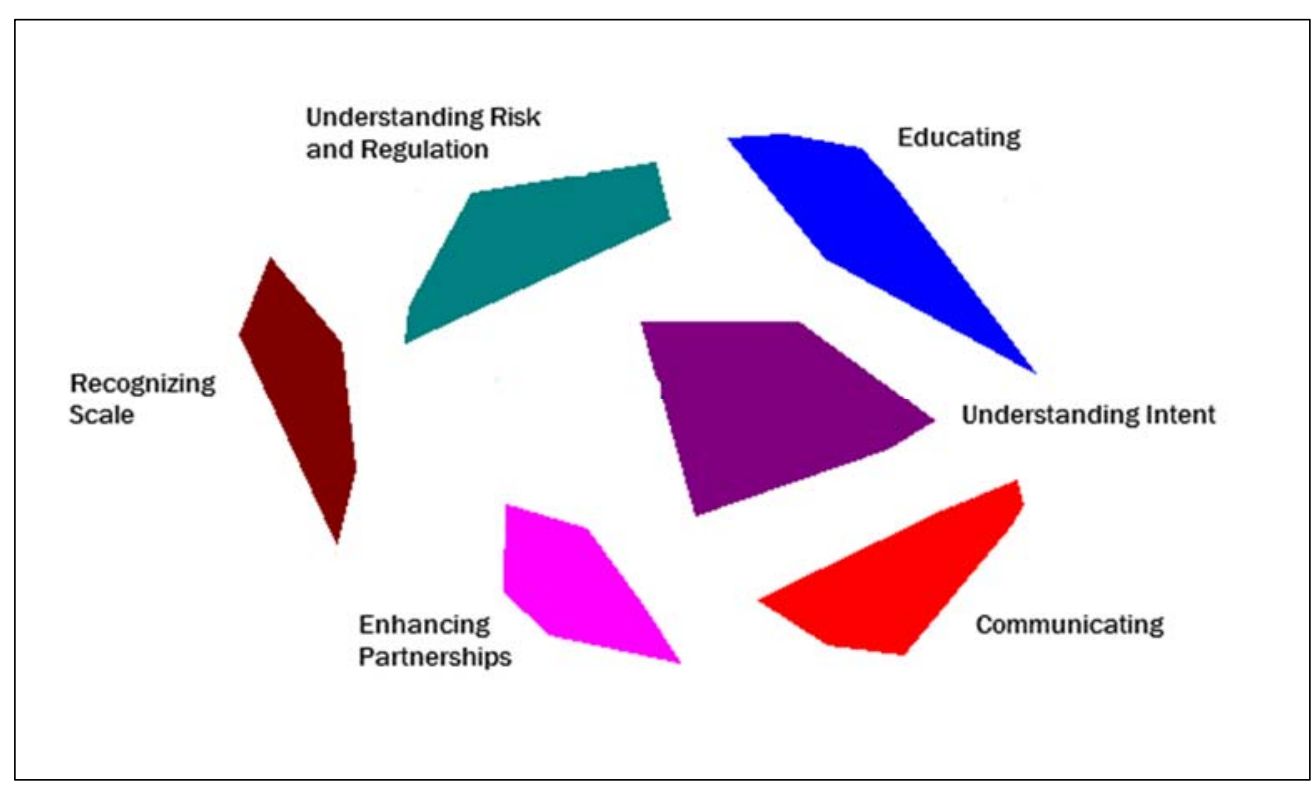

provide the most complete picture of the ideas reflected in them. We asked ourselves if statements in each cluster were better grouped together or if they made more sense when divided.

The "stress index" is the statistic in MDS analysis that indicates goodness-of-fit of the two-dimensional configuration to

Table 1. Demographics of Participants in Concept Mapping $(N=50)$

\begin{tabular}{|c|c|c|}
\hline Question & Answer & No. of Responses \\
\hline \multirow[t]{5}{*}{ Province } & Ontario & 6 \\
\hline & Saskatchewan & 4 \\
\hline & Alberta & 2 \\
\hline & British Columbia & 36 \\
\hline & USA & 2 \\
\hline \multirow[t]{2}{*}{ Work Area } & Food Safety & 17 \\
\hline & Food Security & 33 \\
\hline \multirow[t]{5}{*}{ Work Level } & Federal/National & 3 \\
\hline & Provincial/Territorial & 18 \\
\hline & Municipal and/or Regional & 21 \\
\hline & Student & 2 \\
\hline & Other & 6 \\
\hline \multirow[t]{5}{*}{ Work Sector } & Government & 16 \\
\hline & Nongovernmental Organization & 17 \\
\hline & Private Sector & 3 \\
\hline & Academic/University & 4 \\
\hline & Health Service Delivery & 10 \\
\hline \multirow[t]{7}{*}{ Work Type } & Public Health Practice & 18 \\
\hline & Policy & 1 \\
\hline & Administrative and/or Management & 5 \\
\hline & Advocacy & 11 \\
\hline & Student & 2 \\
\hline & Research & 3 \\
\hline & Other & 10 \\
\hline
\end{tabular}

the original similarity matrix (Kane \& Trochim, 2007). A low stress value suggests a better fit. Trochim and colleagues (2006) specify that approximately $95 \%$ of concept mapping projects have a stress value between 0.205 and 0.365 . The stress value for this data set is 0.239 , which indicates that results were well within the expected range. This means that the two-dimensional point map is a good reflection of how participants grouped the statements.

\section{Results}

Of the 50 participants who submitted statements in response to the focus prompt, two-thirds listed food security as their primary area of work. The larger proportion of food security versus food safety participants should not affect the findings, as sufficient numbers from each group participated and results are averaged such that contributions from each group carry the same weight (Table 1).

Brainstorming resulted in 60 unique statements and six clusters of 
ideas (Figure 2). Participants contributed to naming the clusters, which are (1) communicating, (2) understanding intent, (3) educating, (4) understanding risk and regulation, (5) recognizing scale, and (6) enhancing partnerships. The highest rated statements for each cluster are in Table 2. The following are brief descriptions of each cluster. Comunicating emphasized the importance of finding common ground and language to enhance communication between the two groups. Participants expressed the value of meeting face-to-face to have direct dialogue, starting on a regional level within $\mathrm{BC}$ 's regional health authorities, and then broadening the discussion to include farmers and community food security activists. Some participants suggested recognizing that food safety and community food security work are interdependent could improve communication.

Understanding Intent implied that participants perceive a lack of common understanding between the two sectors about what "food safety" and "community food security" mean, or that each group feels that the other does not fully understand the scope and purpose of their work. Statements

\section{Table 2. Highly Rated Statements by Cluster}

\section{Cluster Name} (No. of Statements)

\section{Communicating} (19 statements)

\section{The best way to ease tensions between those working in food safety and food security is...}

...to find the common ground. Both are essential and mutually compatible, but this requires open communication and flexibility (versus strict rules).

\section{Understanding Intent (18 statements) \\ ...to come to a common understanding of what 'food safety' and 'food security' mean.}

...to ensure a common language for communication so that true dialogue can occur. As someone with some involvement in both sectors, I have seen situations in which both 'sides' are essentially in agreement, but not necessarily realizing it.

...to understand the intents of food safety regulations and safe food handling practices, so that the principles can be applied to food security initiatives; and such initiatives can be achieved.

\section{Educating (11 statements)}

...by providing more reader-friendly information on regulatory environments, especially meat processing. Creating easy-tounderstand messaging around the differences between provincially and federally inspected abattoirs is key to food procurement decision making.

Understanding Risk and Regulation (9 statements)

...for food security professionals to understand the inherent food safety risks in some foods (e.g., raw sprouts, raw milk, dried and/or fermented meats, home canned) and that food regulations are intended to protect broader public health not limit individual choice.

\section{Enhancing Partnerships (7 statements)}

...to form a collaborative group that has authority between food security activists, agriculture sector and health sector that can move this forward rather than the current ad hoc community/regional voluntary groups. ...by holding public information sessions to inform on the value of food security initiatives, the need for food safety to be in place, and what constitutes food safety. ...to look together at the various scales of food production and distribution and consider their impact on both safety and security. In particular to consider what would be appropriate regulations for non-industrial food production/processing. ...to develop awareness of potential bylaws, policies, legislation, bills, and international trade agreements which affect producers and processors - e.g., liability insurance for community gardens, irradiation of produce before selling, or genetically engineered foods.

...to increase opportunities to work together on food policy council and food system initiatives occurring at the municipal level.

...to sort out issues of locality and size to come to mutual understanding that small, local food producers have fundamentally different food safety needs than big industrial food producers. 
indicate that those working in community food security perceive a lack of understanding among those working in food safety about what it means to be food secure in a rural or remote setting. We surmise there may be unique challenges in applying the same safety standard across a vast geographical area with different climate zones and population densities. Additionally, to reduce tension between the groups, participants suggest it is important that intentions of food safety regulations in promoting safe food handling are understood and applied across community food security initiatives. Understanding the intention of each sector in relation to health protection and promotion could help to ease tensions.

The Educating cluster stresses the need to educate the public for a balanced understanding of what constitutes safe and secure food. Participants wanted others to recognize there is no food situation totally without risk. According to some, community food security is about having enough food, local is not necessarily safer than imported, and canned or frozen are acceptable alternatives to fresh. Participants felt education is also needed on different perspectives about what is considered acceptable food and on the meaning of community food security. This cluster, more than others, reflects the divide in the two cultures; some statements were clearly focused on the need to educate for safety, while others clearly showed a preference toward education around community food security.

Understanding Risk and Regulation emphasizes the protection of public health (broadly conceived) and the role of government. Tensions are evident between the groups involving individual choice and protection of the public, a classic public-health tension (Gostin, 2007). A concern was expressed that food safety will trump right-to-eat issues. The problem, it seems, is how to ensure an efficient, economically sound, and safe food system across multiple contexts. Participants suggest removing the word "regulation" from the discussion, referencing the word's negative connotations, while still appreciating the need for broader health protection. This group of statements suggests a better understanding by the general public of the benefits and limitations of broad-based regulations intended for health protection as a way to ease tensions.

Enhancing Partnerships suggests the need to work collectively to develop policy, programs, and guidelines that apply to food activities, and to create working models that illustrate common goals and objectives. Participants referred to a collaborative group, such as a provincial-level food policy council consisting of people from agriculture, health, and grassroots community food security activism can help to identify needs and reduce tensions. We feel it is important to have integrated, multidisciplinary working teams developing policies, recommendations and strategies for the food system.

The final cluster, Recognizing Scale, is the farthest to the left on the map (Figure 1) and well separated from the other clusters, suggesting these statements were rarely, if ever, combined with other statements in the set, thus representing a unique and distinct cluster of strategies. The primary concern reflected in this cluster's statements is that the same regulations are applied to both large and small producers and processors. Participants suggested creating appropriate and separate regulations for non-industrial food production and to sort out issues of locality and size.

\section{Discussion}

Concept mapping offers a unique means to involve a cross-section of interested individuals in a participatory mixed-methods project focusing on a specific question of concern. In the course of this study, concept mapping provided a platform for two diverse groups, those working in food safety and those working in community food security, to share ideas on ways to ease tensions between them. According to the participants, ways to maximize understanding and collaboration between people working in food safety and community food security fall into three broad areas we discuss below: relationships (consisting of the "communicating" and "enhancing partnerships" clusters), education (the "understanding intent," "educating," and "understanding risk and regulations" clusters) and context ("recognizing scale" cluster).

\section{Relationships}

Participants identified a need for a formal process 
for working together to develop policy, programs, and guidelines, such as a collaborative group. The collaborative group needs to have authority balanced between the food security activism sector, agriculture sector, and health sector rather than ad hoc community or regional voluntary groups. Where possible, at the municipal level environmental health officers should have a role on food policy councils along with community nutritionists and community food security activists. This may be more challenging for smaller communities, but food policy councils provide an excellent forum for developing relationships and a venue for a whole food-systems approach to policy. The relationships need to be encouraged in a systematic way locally, regionally, and provincially. This requires health authorities, as employers, to dedicate time to building relationship between these groups. It is as important to develop and maintain good working relationships across professions as it is to foster collaboration between professionals and the community clients they work with on a regular basis. The cross-professional relationships will enhance work done with the community.

The call for intersectoral coordination and collaboration is a key health promotion strategy, as reflected both in public health policy document such as the World Health Organization's Alma Ata Declaration (WHO, 1978) and the Ottawa Charter (International Conference on Health Promotion, 1986). This requires a deliberate strategy with a focus on action. Intersectoral coordination and collaboration are important aspects of a healthy food system, especially given the broad spectrum of individuals who are engaged in food safety and community food security activities. The call by participants in this study for increased communication and enhanced partnership clearly indicates the need for improved intersectoral collaboration.

Research evidence for successful intersectoral collaboration in creating positive alliances is sparse (Dowling, Powell, \& Glendenning, 2004; Green \& Kreuter, 2005; Lawn, Rohde, Rifkin, Were, Paul, \& Chopra, 2008). Stern (1990) wrote about the tensions and contradictions in developing alliances stemming from the "Achieving Health for All" framework (Epp, 1986). These included competition for resources, competition for leadership between professionals, and mistrust by community groups of professional associations and bureaucrats. Stern (1990) advises leaders of alliances to be aware of the need to develop professional credibility toward a common goal, which requires time. Additionally, she encourages debate about each leader's intended outcomes, noting the need for a combination of skills including political, analytical, mediator, facilitator, and communicator. Other challenges include cultural differences, risk orientations, and decision-making styles (Alexander, Christianson, Hearld, Hurley, \& Scanlon, 2010). It can take considerable time and effort to develop trust and respect within a group, and there needs to be full awareness of the challenges that creating an alliance can present.

Forming a new coalition, setting the direction, and specifying goals can be a long and difficult process involving values clarification (Hawe \& Stickney, 1997). There is also a tendency for the health sector to assume others will follow their lead (Hawe \& Stickney, 1997). This can result in increased tension between community food security activists and regulatory authorities because the health sector partner is not meeting others' expectations for collaboration.

\section{Education}

A focus on education surfaced through the clusters of "understanding intent," "educating," and "understanding risk and regulations." Community food security participants identified a general lack of understanding by the food safety sector of how community food security needs are different for those living in urban versus rural settings in terms of access, and a lack of food safety policy tailored for rural settings. Physical and social environments affect food access. In rural areas, there is less access, in both a physical and economic sense, to the mainstream food system that supplies urban areas (Smith \& Morton, 2009). Rural low-income households have more frequent nonmarket food exchanges than urban low-income households, and small-scale food production is the most economical way to provide healthy food in rural environments (Morton, Bitto, Oakland, \& Sand, 2008). Under- 
standing community food security needs in different settings is important for a comprehensive approach to the food system.

Similarly, there is a lack of understanding by those working in community food security about what it takes to create and maintain a safe food system. Food safety guidelines are intended to prevent and reduce incidents of foodborne illness. More than knowing how to apply rules or guidelines, understanding what it takes to create and support a safe food supply is key. The regulatory environment is challenging to the average person. Demystifying regulations is one way to bridge the gap between those who enforce regulations and those who work in the environments being regulated. Using plain language in food safety regulations may be one way to demystify the process. Some researchers (Mackey \& Metz, 2009; Mills et al., 2004) have addressed the idea of food product labels being easy to read regarding safety, nutrition, and allergens, but there is no evidence that food safety regulations, such as what might be in a public health act, are being put into plain language. Participants suggested more work to clarify regulatory documents to improve communication between regulators and lay people. While it is not the role of regulating bodies to explain regulations in plain language, perhaps there is a need for a new role of "translator" in the regulatory arena, either through formal government channels or nongovernmental organizations.

The final element of the education area is the role of public health in protecting the public from disease as well as protecting the right to food and preserving the opportunity for individual choice. Some participants perceive a conflict between food safety regulations that limit access to certain kinds of food considered risky, and the right to eat what one chooses. This conflict may exist because some people value a precautionary principle approach and focus on the safety aspect of food, while others perceive the risk of foodborne illness as minimal and perceive the restraints on food access resulting from safety regulations as impeding the health and well-being of individuals and communities. These are complicated and value-laden issues requiring relationship building, trust, and respect in order to reach a balance.

\section{Context}

The final cluster is "recognizing scale." This cluster is most important to those working in community food security and least important to those working in food safety. We consider it "context" because in the current system, the same regulations apply regardless of context; the same regulations apply to large-scale food production as to small-scale food production, despite differing levels of risk associated with each. This one-size-fits-all regulatory approach designed for large-scale production makes it difficult for small-scale producers to comply with standards. Seed (2011) refers to the issue of scale, in terms of regulation standardization, as a subject of power. According to Dahlberg (2001), standardization allows for a structurally simple, and therefore more easily dominated, society. The tension here is clear; one group (food safety) strives for simplicity in a centralized system that thrives on power, while the other (community food security) is seeking flexibility in a diffused power setting, which adds a level of complexity beyond the capacity of the current system. Changes in food safety system capacity would be needed to support the smaller-scale context rather than imposing blanket regulations that are applied for the sake of simplicity.

\section{Recommendations}

There is a growing interest in community food security, yet increased tensions are a real possibility unless we acknowledge the problem and take action to work better together. We have identified four areas of focus for easing tensions.

First, there is a need to form a collaborative group at a high regulatory level that shares authority among the community food security activist sector, agriculture sector, and health sector. This level of collaboration could work on a broad scope of food-related activities and mitigate problems in early stages. Similarly, where possible, food policy councils at the municipal level should include a food safety specialist along with community nutritionists and community food security activists.

Second, relationships need to be encouraged in a systematic way locally, regionally, and provincially, and this requires dedicated time to be allocated by the health authority. Building relationships 
takes time, and this activity needs to be recognized as a valuable part of work.

Third, reader-friendly information is needed on regulatory environments in order to facilitate food procurement decision-making and understanding by small-scale processors. More plain language documents or web-based information can help to demystify the regulation process. Finally, there is a need to increase food safety system capacity to allow for flexibility in regulations to match the context of the small food producer. A one-size-fits-all approach may be efficient, but it lacks effectiveness. Allowing for flexibility or context-specific regulations will require more time for food safety inspectors. Further research exploring these priorities is necessary to determine their value and success.

There are no easy or quick means to ease tensions between those working in food safety and community food security, but we have numerous practical and positive ideas to work better together. On a positive note, there was no mention by participants of distrust between the individuals, and there is a general recognition of the value of both food safety and food security for a healthy food system. Building better relationships and improving education are achievable goals. Dealing with context and resolving issues of power require further investigation. While it is challenging, considering all these aspects may result in positive long-term outcomes.

\section{References}

Alexander, J. A., Christianson, J. B., Hearld, L. R., Hurley, R., \& Scanlon, D. P. (2010). Challenges of capacity building in multisector community health alliances. Health Education \& Behavior, 37(5), 645664. http://dx.doi.org/10.1177/1090198110363883

Anderson, C. (2013, September 12). Muddying the waters. Experts, citizens, and food sovereignty. A commentary/analysis [Blog post]. Retrieved from http://realmanitobafoodfight.ca/2013/09/12/mud dying-waters-experts-citizens-food-sovereigntycommentaryanalysis/

Buckley, J. A. (2015). Food safety regulation and small processing: A case study of interactions between processors and inspectors. Food Policy, 51, 74-82. http://dx.doi.org/10.1016/i.foodpol.2014.12.009
CBC News. (2013, August 30). Manitoba inspectors seize farm's award-winning meats. Retrieved from http://www.cbc.ca/news/canada/manitoba/manit oba-inspectors-seize-farm-s-award-winning-meats$\underline{1.1359057}$

Clarke, A. E. (2005). Situational analysis: Grounded theory after the postmodern turn. Thousand Oaks, California: SAGE Publications.

da Cruz, F. T., \& Menasche, R. (2014). Tradition and diversity jeopardised by food safety regulations? The Serrano Cheese case, Campos de Cima da Serra region, Brazil. Food Policy, 45, 116-124. http://dx.doi.org/10.1016/j.foodpol.2013.04.014

Dahlberg, K. A. (2001). Democratizing society and food systems: Or how do we transform modern structures of power? Agriculture and Human Values, 18(2), 135-151. http://dx.doi.org/10.1023/A:1011175626010

Dodds, R., Holmes, M., Arunsopha, V., Chin, N., Le, T., Maung, S., \& Shum, M. (2014). Consumer choice and farmers' markets. Journal of Agricultural and Environmental Etbics, 27(3), 397-416. http://dx.doi.org/10.1007/s10806-013-9469-4

Dowling, B., Powell, M., \& Glendenning, C. (2004). Conceptualising successful partnerships. Health \& Social Care in the Community, 12(4), 309-317. http://dx.doi.org/10.1111/j.13652524.2004.00500.x

Epp, J. (1986). Achieving health for all: A framework for bealth promotion. Ottawa, Ontario, Canada: Health and Welfare Canada.

Food Safety Act Meat Inspection Regulation, British Columbia Laws, British Columbia, Reg. 349/2004 Stat. (2004).

Goldberg, R. L. (2012). Administering real food: How the eat-food movement should—and should notapproach government regulation. Ecology Law Quarterly, 39(3), 773-828. http://dx.doi.org/10.15779/Z38ZZ76

Gostin, L. O. (2007). General justifications for public health regulation. Public Health, 121(11), 829-834. http://dx.doi.org/10.1016/j.puhe.2007.07.013

Green, L. W., \& Kreuter, M. W. (2005). Health program planning: An educational and ecological approach. New York: McGraw-Hill.

Hamm, M. W., \& Bellows, A. C. (2003). Community food security and nutrition educators. Journal of Nutrition Education and Behavior, 35(1), 37-43. http://dx.doi.org/10.1016/S1499-4046(06)60325-4 
Hawe, P., \& Stickney, E. K. (1997). Developing the effectiveness of an intersectoral food policy coalition through formative evaluation. Health Education Research, 12(2), 213-225. http://dx.doi.org/10.1093/her/12.2.213

Hughes, K. (2010). An examination of the potential impacts of food safety management programs on community farms (Master's thesis, University of Victoria). Retrieved from http://hdl.handle.net/1828/3874

International Conference on Health Promotion. (1986). Ottawa Charter for Health Promotion. Canadian Journal of Public Health, 77(6), 425-430.

Johnson, B. (2008). Impact of the meat inspection regulation on slaughter capacity in the North Okanagan Regional district (RDNO). Vernon, BC: Community Futures North Okanagan. Retrieved from http://www.socialplanning.ca/pdf/food_security/ meat_inspection_summary_report.pdf

Kane, M., \& Trochim, W. M. K. (2007). Concept mapping for planning and evaluation. Thousand Oaks, California: SAGE Publications.

Lawn, J. E., Rohde, J., Rifkin, S., Were, M., Paul, V. K., \& Chopra, M. (2008). Alma-Ata 30 years on: Revolutionary, relevant, and time to revitalise. The Lancet, 372(9642), 917-927. http://dx.doi.org/10.1016/S0140-6736(08)61402-6

Mackey, M. A., \& Metz, M. (2009). Ease of reading of mandatory information on Canadian food product labels. International Journal of Consumer Studies, 33(4), 369-381. http://dx.doi.org/10.1111/j.14706431.2009.00787.x

Martin, W. L. (2014). Food gone foul? Food safety and security tensions (Doctoral dissertation, University of Victoria). Retrieved from https://dspace.library.uvic.ca/bitstream/handle/18 28/5193/Martin Wanda PHD 2014.pdf

McMahon, M. (2011). Standard fare or fairer standards: Feminist reflections on agri-food governance. Agriculture and Human V alues, 28(3), 401-412. http://dx.doi.org/10.1007/s10460-009-9249-y

Mills, E. N. C., Valovirta, E., Madsen, C., Taylor, S. L., Vieths, S., Anklam, E.,...Frewer, L. (2004). Information provision for allergic consumersWhere are we going with food allergen labelling? Allergy, 59(12), 1262-1268. http://dx.doi.org/ 10.1111/j.1398-9995.2004.00720.x

Morris, J. G. (2011). How safe is our food? Emerging Infectious Diseases, 17(1), 126-128. http://dx.doi.org/10.3201/eid1701.101821
Morton, L. W., Bitto, E. A., Oakland, M. J., \& Sand, M. (2008). Accessing food resources: Rural and urban patterns of giving and getting food. Agriculture and Human Values, 25(1), 107-119. http://dx.doi.org/10.1007/s10460-007-9095-8

Mount, P., Hazen, S., Holmes, S., Fraser, E., Winson, A., Knezevic, I.,...Landman, K. (2013). Barriers to the local food movement: Ontario's community food projects and the capacity for convergence. Local Environment, 18(5), 592-605. http://dx.doi.org/10.1080/13549839.2013.788492

Nestle, M. (2003). Safe food: Bacteria, biotechnology, and bioterrorism. Oakland: University of California Press.

Rideout, K., Seed, B., \& Ostry, A. (2006). Putting food on the public health table: Making food security relevant to regional health authorities. Canadian Journal of Public Health, 97(3), 233-236. http://journal.cpha.ca/index.php/cjph/article/ view $/ 734 / 734$

Seed, B. (2011). Food security in public health and other government programs in British Columbia, Canada: A policy analysis (Doctoral dissertation, City University, London). Retrieved from http://openaccess.city.ac.uk/1173/

Smith, C., \& Morton, L. W. (2009). Rural food deserts: Low-income perspectives on food access in Minnesota and Iowa. Journal of Nutrition Education and Behavior, 41(3), 176-187. http://dx.doi.org/10.1016/j.jneb.2008.06.008

Stern, R. (1990). Healthy communities: Reflections on building alliances in Canada. A view from the middle. Health Promotion International, 5(3), 225-231. http://dx.doi.org/10.1093/heapro/5.3.225

Thomas, M. K., Murray, R., Flockhart, L., Pintar, K., Pollari, F., Fazil, A.,...Marshall, B. (2013). Estimates of the burden of foodborne illness in Canada for 30 specified pathogens and unspecified agents, Circa 2006. Foodborne Pathogens and Disease, 10(7), 639-648. http://dx.doi.org/10.1089/fpd.2012.1389

Trochim, W. M. K. (1989). An introduction to concept mapping for planning and evaluation. Evaluation Program Planning, 12(1), 1-16. http://dx.doi.org/10.1016/0149-7189(89)90016-5

Trochim, W. M., Cabrera, D. A., Milstein, B., Gallagher, R. S., \& Leischow, S. J. (2006). Practical challenges of systems thinking and modeling in public health. American Journal of Public Health, 96(3), 538-546. http://dx.doi.org/10.2105/AJPH.2005.066001 
Weatherill, S. (2009). Report of the independent investigator into the 2008 Listeriosis outbreak. Ottawa, Ontario: Government of Canada. Retrieved from http:// news.gc.ca/web/article-en.do?nid=468909

World Health Organization [WHO]. (1978). Declaration of Alma-Ata. Retrieved from

http://www.euro.who.int/__data/assets/pdf_file/ 0009/113877/E93944.pdf?ua=1
Worosz, M. R., Knight, A. J., Harris, C. K., \& Conner, D. S. (2008). Barriers to entry into the specialty red meat sector: The role of food safety regulation. Southern Rural Sociology, 23(1), 170-207. http://www.ag.auburn.edu/auxiliary/srsa/pages/A rticles/SRS $\% 202008 \% 2023 / 1 /$ SRS $\% 202008 \% 2023$ \%201\%20170-207.pdf 